\title{
Is vibration white finger a primary sympathetic nerve injury?
}

\author{
LENA EKENVALL, L E LINDBLAD
}

From the Departments of Occupational Medicine and Clinical Physiology, Södersjukhuset, Stockholm, Sweden

ABSTRACT Changes in the sympathetic nerve system have been suggested as the pathophysiological mechanism underlying vibration white finger (VWF). The aim of the present study was to investigate if experimental support for such a mechanism could be found in VWF. Drugs with a known effect on sympathetic alpha receptors were administered into the finger skin by iontophoresis and their effects on blood flow in the same area evaluated using a laser Doppler technique. The effects of noradrenaline (stimulating alpha-1 and alpha-2 receptors), phenylephrine (an alpha-1 stimulator), and B-HT 933 (an alpha-2 stimulator) were studied in 12 patients with vibration white finger and 12 healthy controls. The reactions to noradrenaline and B-HT 933 were similar in both patients and controls, but the reaction of the patients to phenylephrine was significantly weaker than the controls. In additional experiments in six patients and six controls concentration effect curves to phenylephrine were derived. The curves for the patients were shifted to the right-that is, they reacted less strongly than the controls at all doses of the drug which induced an appreciable vasoconstriction. The results of this study are compatible with the hypothesis that the alpha-1 receptor mediated responses are weakened in VWF. The predominance of alpha-2 receptors in the digital arteries has, on the basis of animal experiments, been suggested as a possible mechanism for Raynaud's phenomenon.

Constriction of the blood vessels is mediated through the sympathetic nerve fibres and many theories concerning the aetiology of Raynaud's phenomenon have implicated changes in the sympathetic nerve system. Raynaud himself proposed that the attacks in the primary disease were due to overactivity in sympathetic nerves. ${ }^{1}$ Lewis assumed that the sympathetic nerve endings were affected with an increased sensitivity to cold $^{2}$ whereas Magos and Okos suggested that the hypersensitivity to cold in vibration white finger (VWF) was caused by the accumulation of vasoactive substances in the walls of the vessels. ${ }^{3}$

The postsynaptic alpha-adrenergic receptors that mediate vasoconstriction are of two subtypes, alpha-1 and alpha-2, characterised by a different reactivity to agonistic and antagonistic drugs. ${ }^{4}$ Thus alpha-1receptors are preferentially stimulated by phenylephrine and blocked by prazosin whereas alpha-2receptors are preferentially stimulated by B-HT 933 (azepexole) and blocked by yohimbine. ${ }^{5}$ Some vessels seem to have adrenoceptors of only one subtype whereas others seem to have a mixed receptor population. ${ }^{6}$ The existence of vascular alpha-1 and alpha-2

Accepted 3 March 1986 receptors has been shown in vivo in $\operatorname{man}^{78}$ and postsynaptic alpha-receptors of both subtypes coexist in human digital vessels (JP Cooke et al, personal communication; unpublished results).

The study presented here was performed to determine whether or not alpha-adrenergic responses in the small finger skin vessels are altered in VWF and if any change in the response could be linked to a specific subtype of receptor.

\section{Subjects and methods}

Twelve patients with VWF were examined in the first set of experiments. They were in grade 2 or 3 according to the Taylor Pelmear symptom scale, ${ }^{9}$ and the disease had been verified by a pathological reaction to a cold provocation test. ${ }^{10}$ Apart from VWF the patients were healthy and were taking no drugs. Twelve healthy men not exposed to vibrating tools were used as controls. Informed consent was obtained from all subjects, and the design of the study was approved by the local ethical committee.

A recently developed technique for the local application of vasoactive drugs into the skin with simultaneous measurement of the blood flow in the same skin area was used (LE Lindblad et al, unpublished 


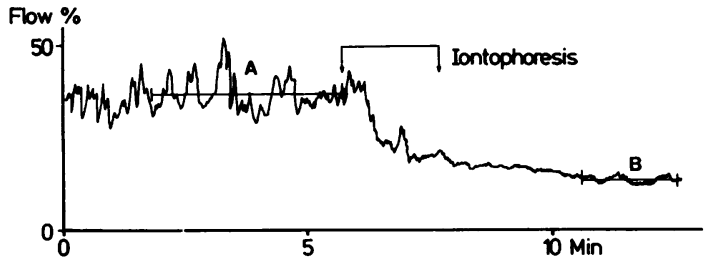

Fig 1 Analysis curve of a flow meter recording. Effect of drug on blood flow is calculated as $(B / A) .100$.

results). Substances with known effects on alpha-1and alpha-2-receptors were introduced locally into the skin by an electric current (iontophoresis). Skin blood flow was registered with a laser Doppler technique (Periflux, Perimed, KB) before, during, and after the iontophoresis, and the result was registered on a strip chart recorder (GILA 401112, DLH Laumann) and a data logger (domestically produced). The signals from the data logger were analysed off line on a desk computer (HP 9856 B) with a sampling frequency of $20 \mathrm{~Hz}$.

The laser Doppler technique gives only relative flow values and the change in flow has been calculated as the quotient between the flow after drug administration and the basal flow (B/A 100 in fig 1). The basal flow was calculated as an average of the flow during the last four minutes before the start of the iontophoresis; the flow after drug administration was calculated from the last two minutes of the experiment (fig 1).

The substances administered by iontophoresis were noradrenaline- $\mathrm{HCl}$ (Sigma Chemicals) $1 \mu \mathrm{mol} / \mathrm{ml}$, phenylephrine (Sigma Chemicals) $1 \mu \mathrm{mol} / \mathrm{ml}$, and BHT 933 (Boehringer Ingelheim) $10 \mu \mathrm{mol} / \mathrm{ml}$; all were dissolved in deionised water. In a pilot study on six healthy male volunteers the concentrations used were found to be the lowest that caused reduction of blood flow and visible blanching of the skin. In a second set of experiments phenylephrine concentrations from $0.01 \mu \mathrm{mol} / \mathrm{ml}$ to $100 \mu \mathrm{mol} / \mathrm{ml}$ were studied to derive concentration effect curves.

The subjects were examined in a supine position. The probe holder was mounted on the dorsal side of the middle phalanx of the fourth finger. Skin temperature was registered and if less than $30^{\circ} \mathrm{C}$ the subject was warmed with a blanket before the start of the experiment until the finger temperature was above $30^{\circ} \mathrm{C}$. To get a steady state circulation in the skin precautions were taken to prevent external disturbances during the experiments.

The first drug was introduced into the chamber and blood flow was registered for 15 minutes before the current (200 $\mu$ A DC) was switched on. Iontophoretic administration of the drug into the skin was performed for two minutes. Blood flow was monitored during and five minutes after the iontophoresis. The chamber was then moved to the third finger and the procedure was repeated with the second substance. The third substance was administered into the skin of the second finger. Blood flow was measured for five minutes before the new experiments. The drugs were administered in random order.

To verify the result obtained with phenylephrine in the study outlined above, a second set of experiments was designed. Six patients with vibration white finger and six healthy controls were examined in order to obtain concentration effect curves to phenylephrine. The chamber was mounted on the third finger, blood flow was registered for five minutes, and iontophoresis with phenylephrine $0,01 \mu \mathrm{mol} / \mathrm{ml}$ was applied for two minutes. The current was switched off

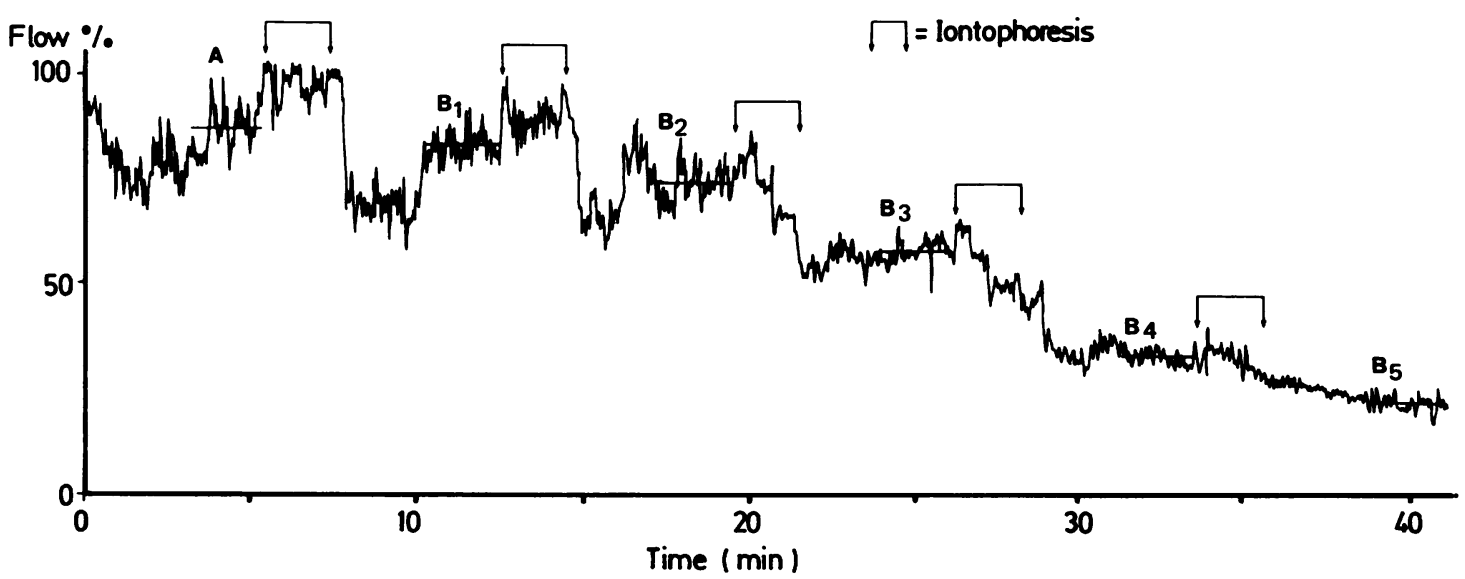

Fig 2 Analysis curve of a phenylephrine concentration effect experiment. Effect of $0.01 \mu \mathrm{mol} / \mathrm{ml}$ is calculated as (B $/ A)$. 100 , effect of $0 \cdot 1 \mu \mathrm{mol} / \mathrm{ml}$ as $\left(B_{2} / A\right) .100$, and so on. 
and the chamber was then immediately filled with phenylephrine $0,1 \mu \mathrm{mol} / \mathrm{ml}$ without changing its position. Blood flow was registered again for five minutes before the current was switched on for two minutes. In the same way the experiment was continued with phenylephrine $1 \mu \mathrm{mol} / \mathrm{ml}, 10 \mu \mathrm{mol} / \mathrm{ml}$, and, in the patient group, $100 \mu \mathrm{mol} / \mathrm{ml}$.

The change in blood flow was calculated from the two minutes preceeding the first period of iontophoresis (A, fig 2) and two minutes before each of the following periods $\left(\mathbf{B}_{1}-\mathbf{B}_{4}\right.$, fig 2$)$ and the last two minutes of the experiment $\left(B_{5}\right)$ as the quotient between $B$ and A (fig 2). For statistical analysis, Mann-Whitney's two sample rank test was used (two sided $\mathrm{p}$ values).

\section{Results}

There was no difference between the patients and controls with regard to finger temperature. One patient and one control subject did not react to any of the substances administered and were excluded from the study on the suspicion of a technical fault. In the remaining subjects noradrenaline caused a pronounced vasoconstriction with visible blanching of the skin area under the chamber (fig 3); this was identical in patients and controls.

In the controls the alpha-1 agonist phenylephrine

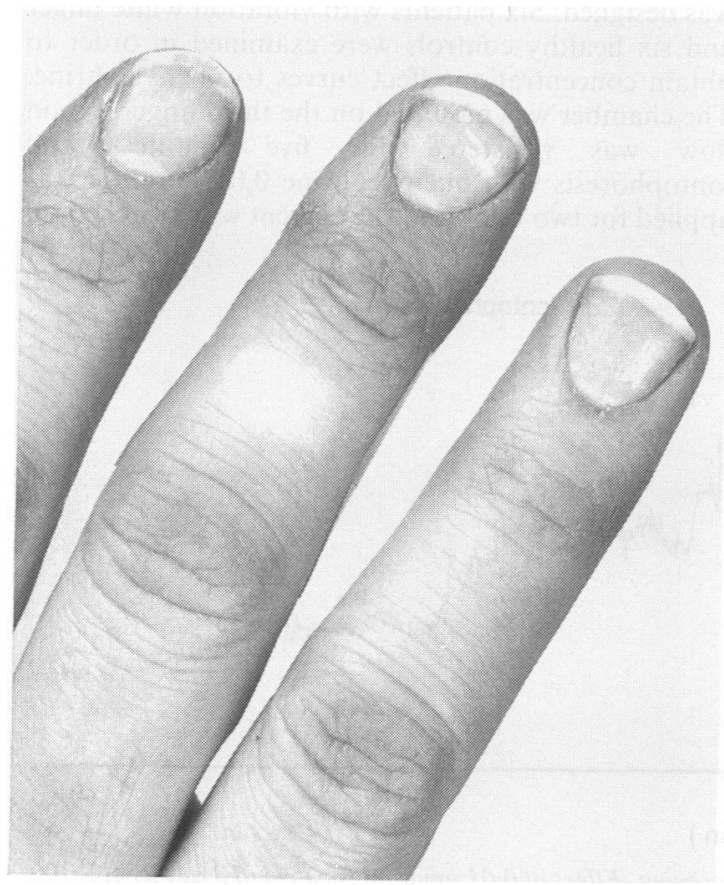

Fig 3 Noradrenaline induced blanching of a finger.

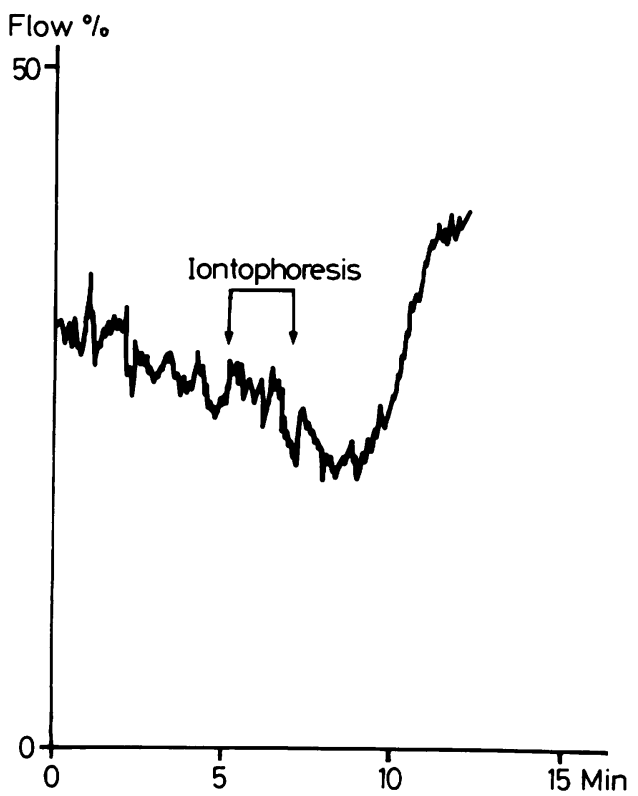

Fig 4 Blood flow recording of a patient after iontophoresis with phenylephrine $1 \mathrm{\mu mol} / \mathrm{ml}$.

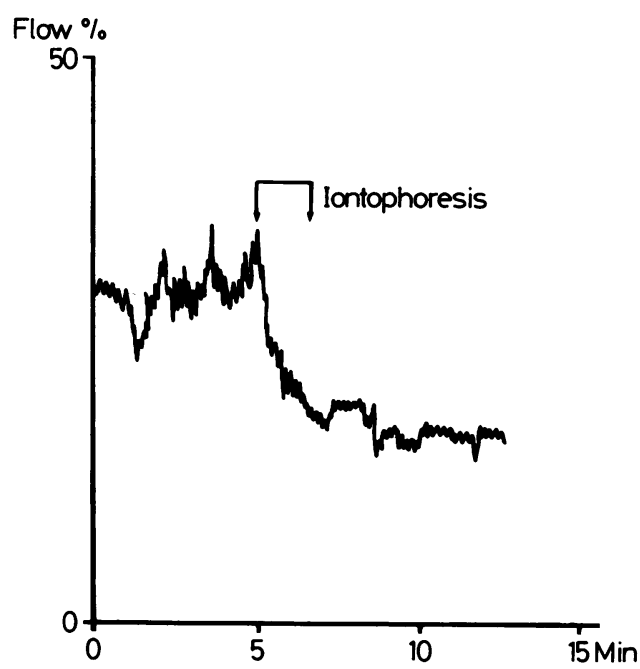

Fig 5 Blood flow recording of a patient after iontophoresis with phenylephrine $1 \mathrm{\mu mol} / \mathrm{ml}$.

always caused vasoconstriction. In the patient group, however, administration of this substance caused a less pronounced decrease in blood flow than in the control group, and the reactions in individual patients varied from an increase (fig 4) to a decrease in blood flow (fig 5). The difference between patients and controls was statistically significant $(p<0.025)$. 


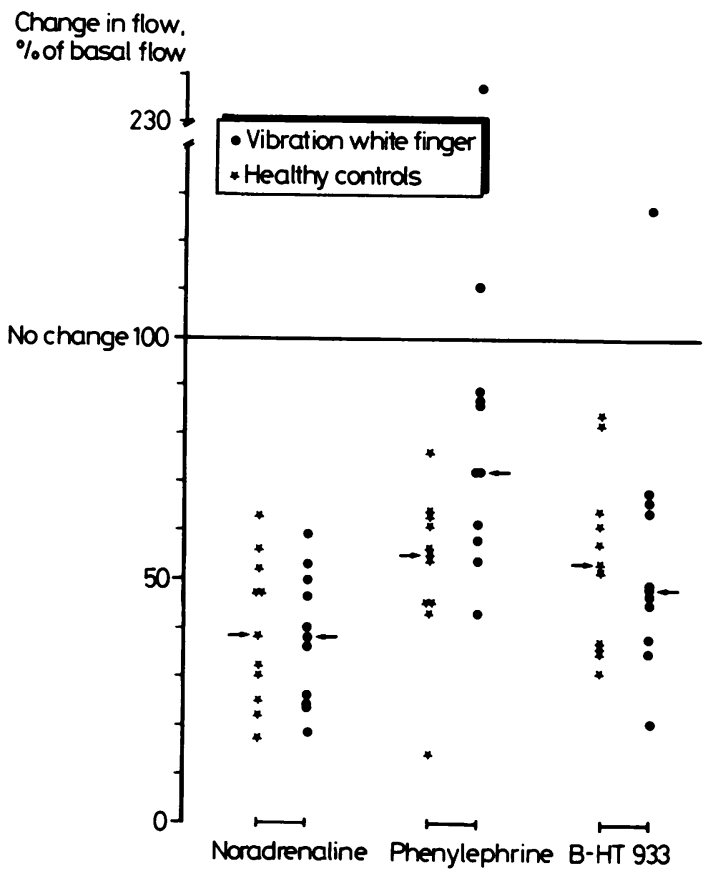

Fig 6 Effect of iontophoretically administered noradrenaline, phenylephrine, and B-HT 933 in healthy controls $\left(^{*}\right)$ and patients with $V W F(\bigcirc)$. Individual values are shown and medians are indicated by arrows.

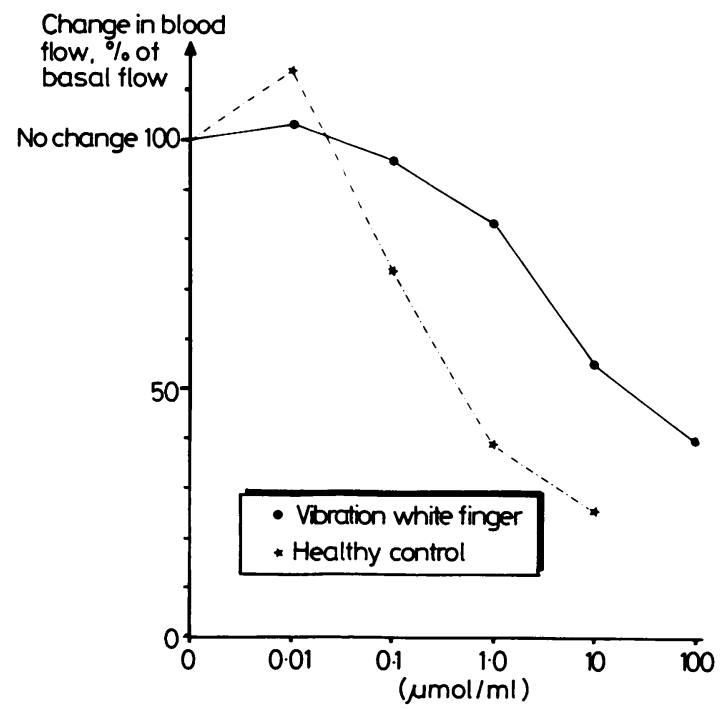

Fig 7 Concentration effect of phenylephrine in healthy controls (*....*) and in patients with $V W F\left(O_{-}\right)$). Median change in flow is shown at each concentration of drug. $X$-axis has a logarithmic scale.
The alpha-2 agonist, B-HT 933, induced a vasoconstriction in all the controls. One of the patients had a slight increase in blood flow, but in the others the drug produced vasoconstriction. There was no significant difference between the reactions of patients and controls (fig 6).

The result of the concentration effect experiments is shown in fig 7. The reactions of the patients were less pronounced than those of the controls and the differences between patients and controls were significant at 1 and $10 \mu \mathrm{mol} / \mathrm{ml}(\mathrm{p}<0.025$ resp $<$ 0.005).

\section{Discussion}

Vasoconstriction induced by alpha-1 activity is reduced and that induced by alpha-2 activity is augmented by cooling. ${ }^{11}$ In a vessel preparation with only alpha- 2 receptors, obtained by blocking with an alpha-1 antagonist, cooling increases the contractile responses to noradrenaline. ${ }^{11}$ Thus in subjects preferentially having alpha- 2 receptors in the digital vessels, cooling might lead to an exaggerated response. This has, on a theoretical basis, been suggested as a possible mechanism for Raynaud's phenomen. ${ }^{12}$

In the present study patients with VWF reacted significantly weaker, on a group basis, than controls to an alpha-1 stimulator, phenylephrine, whereas there were no significant differences in their reactions to noradrenaline or B-HT 933. The concentration effect curves for phenylephrine were shifted to the right in VWF patients compared with the controls. Thus both sets of experiments support the hypothesis that the patients with VWF have a reduced response to alpha-1 receptor stimulation.

The weaker reaction to phenylephrine in VWF does not seem to depend on differences in skin permeability due, for example, to increased thickness of the skin, since the reactions to the other drugs were similar in the two groups. Alpha-1 mediated vasoconstriction decreases on cooling, but there was no difference in finger temperature between patients and controls that could explain the results. The results, however, are compatible with a diminished alpha-1 responsiveness in the small cutaneous blood vessels in the finger. A possible explanation could be a damage of alpha-1 receptors due to vibration trauma.

Two patients had a vasodilatation after iontophoretically administered phenylephrine and one after B-HT 933. This might be a chance phenomenon but was not seen in any of the controls.

There are many indications for nerve injury in the vibration syndrome. ${ }^{13-15}$ It has been suggested that the receptors in direct contact with sympathetic nerve endings are of the alpha-1 subtype, ${ }^{16}$ whereas the alpha-2-receptors are considered to be localised closer 
to the lumen of the vessels. ${ }^{17}$ The present results are compatible with the hypothesis that Raynaud's phenomenon in VWF is due to an injury of the alpha-1 adrenoceptors. The predominance of alpha-2 receptors cause the vasoconstriction induced by cooling to be exaggerated when the modulating effect of the alpha-1-receptors is decreased.

We thank Britt-Marie Etzell for highly skilled technical help.

This work was supported by a grant from the Swedish Work and Environment Fund.

\section{References}

1 Raynaud M. New researches on the nature and treatment of local asphyxia of the extremities. London: New Sydenhamn Society, 1888 (selected monographs): 153-83.

2 Lewis T. Vascular disorders of the limbs. 2nd ed. London: Macmillan, 1949.

3 Magos L, Okos G. Cold dilatation and Raynaud's phenomenon. Arch Environ Health 1963;7:402-10.

4 Starke K, Docherty JR. Alpha 1 - and alpha 2 -adrenoceptors: pharmacology and clinical implications. J Cardiovasc Pharmacol 1981;3:S14-23.

5 Timmermans PBMWM, van Zwieten PA. Postsynaptic alpha ${ }_{1-}^{-}$ and alpha $a_{2}$-adrenoceptors in the circulatory system of the pithed rat: selective stimulation of the alpha ${ }_{2}$-type by B-HT 933. Eur J Pharmacol 1980;63:199-202.

6 De Mey J, Vanhoutte PM. Uneven distribution of postjunctional alpha $_{1}$ - and alpha ${ }_{2}$-like adrenoceptors in canine arterial and venous smooth muscle. Circ Res 1981;48:875-84.

7 Goldberg MR, Robertson D. Evidence for the existence of vascular alpha $a_{2}$-adrenergic receptors in humans. Hypertension 1984;6:551-6.

8 Jie K, van Brummelen P, Vermey P, Timmermans PBMWM, van Zwieten PA. Identification of vascular postsynaptic alpha ${ }_{1}$ and alpha ${ }_{2}$-adrenoceptors in man. Circ Res 1984;54:447-52.

9 Taylor W, Pelmear PL, eds. Vibration white finger in industry. London: Academic Press, 1975:xxi.

10 Ekenvall L, Lindblad LE. Digital blood pressure after local cooling as a diagnostic tool in traumatic vasospastic disease. $\mathrm{Br} \mathrm{J}$ Ind Med 1982;39:388-91.

11 Flavahan NA, Lindblad LE, Verbeuren TJ, Shepherd JT, Vanhoutte PM. Cooling and alpha $1_{1}$ - and alpha ${ }_{2}$-adrenergic responses in cutaneous veins: role of receptor reserve. Am Physiol 1985;249:H950-5.

12 Vanhoutte PM, Cooke JP, Lindblad LE, Shepherd JT, Flavahan NA. Modulation of postjunctional alpha-adrenergic responsiveness by local changes in temperature. Clin Sci 1985;68:121-35.

13 Chatterjee DS, Barwick DD, Petrie A. Exploratory electromyography in the study of vibration-induced white finger in rock drillers. Br J Ind Med 1982;39:89-97.

14 Lukáš E, Kužel V, Nedvídková H. Vergleich der Untersuchungsergebnisse der Leitungsgeschwindigkeit in den motorischen und sensitiven Fasern des $\mathrm{N}$ ulnaris und $\mathrm{N}$ medianus bei Personen mit professioneller und nichtprofessioneller Vasoneurose. Int Arch Occup Environ Health 1977;38:283-94.

15 Alaranta H, Seppäläinen AM. Neuropathy and the automatic analysis of electromyographic signals from vibration exposed workers. Scand J Work Environ Health 1977;3:128-34.

16 Langer SZ, Shepperson NB, Massingham R. Preferential noradrenergic innervation of alpha-adrenergic receptors in vascular smooth muscle. Hypertension 1981;3:1-112-118.

17 Langer SZ, Hicks PE. Alpha-adrenoreceptor subtypes in blood vessels: physiology and pharmacology. $J$ Cardiovas Pharmacol 1984;6:S547-58. 